\title{
Does IQ explain socioeconomic inequalities in health? Evidence from a population based cohort study in the west of Scotland
}

\author{
G David Batty, Geoff Der, Sally Macintyre, Ian J Deary
}

\begin{abstract}
Objective To test the hypothesis that IQ is a fundamental cause of socioeconomic inequalities in health.

Design Cross sectional and prospective cohort study, in which indicators of IQ were assessed by written test and

socioeconomic position by self report.

Setting West of Scotland.

Participants 1347 people (739 women) aged 56 in 1987.

Main outcome measures Total mortality and coronary heart disease mortality (ascertained between 1987 and 2004); respiratory function, self reported minor psychiatric morbidity, long term illness, and self perceived health (all assessed in 1988).

Results In sex adjusted analyses, indices of socioeconomic position (childhood and current social class, education, income, and area deprivation) were significantly associated with each health outcome. Thus the greatest risk of ill health and mortality was evident in the most socioeconomically disadvantaged groups, as expected. After adjustment for IQ, a marked attenuation in risk occurred for poor mental health (range of attenuation in risk ratio across the five socioeconomic indicators: $15-58 \%$ ), long term illness (25-53\%), poor self perceived health (41-56\%), respiratory function (44-66\%), coronary heart disease mortality (31-111\%), and total mortality (45-131\%). Despite the clear reduction in the magnitude of these effects after controlling for IQ, in half of the associations examined the risk of ill health in socioeconomically disadvantaged people was still at least twice that of advantaged people. Statistical significance was lost for only $5 / 25$ separate socioeconomic health gradients that showed significant relations in sex adjusted analyses.

Conclusions Scores from the IQ test used here did not completely explain the socioeconomic gradients in health. However, controlling for IQ did lead to a marked reduction in the magnitude of these gradients. Further exploration of the currently scant information about IQ, socioeconomic position, and health is needed.
\end{abstract}

\section{Introduction}

Reduction of socioeconomic inequalities in health, well documented in developed countries, is a target for many governments, including those of the United Kingdom and United States, ${ }^{1-3}$ and for the World Health Organization, which has recently established the Global Commission on Social Determinants of Health. ${ }^{45}$ Understanding the underlying causes of socioeconomic gradients in health is crucial if population based interventions are to be effective. ${ }^{6}$
Explanations for socioeconomic gradients in health have traditionally focused on access to resources (such as education and income), physical exposures in the living and working environment (such as housing conditions and toxins), and health related behaviours (such as smoking and diet). ${ }^{5}$ That controlling for such plausible mediating risk factors reduces but does not eradicate socioeconomic differentials in health has prompted speculation that as yet unmeasured psychological factors need to be taken into account in explaining how poverty "get[s] under the skin."

One novel hypothesis is that intelligence (denoted here as IQ) might be: "the epidemiologists' elusive 'fundamental cause' of social class inequalities in health." ${ }^{\prime \prime}$ This suggestion is based on observations that low IQ scores ascertained in childhood, ${ }^{10-12}$ early adulthood, ${ }^{13}$ mid-life, ${ }^{14}$ and older age ${ }^{16}$ are associated with elevated rates of later death and disease; IQ scores are socially patterned $^{17}$; and a link exists between functional literacy (a correlate of IQ) and health related behaviours, injuries, and self management of illness. ${ }^{9}$

This hypothesis can be tested very simply. If it is correct, adjusting the relation between socioeconomic position and health for IQ would remove the association. To date, this hypothesis has been examined only in the second Whitehall study, where some attenuation of the socioeconomic position-health gradient was apparent, although statistical significance at conventional levels was generally retained. ${ }^{18}$ In this paper we extend these findings by reporting analyses of data from a general population based sample of people with prospectively gathered information on all cause mortality and mortality due to coronary heart disease. We selected these health outcomes, which were unavailable in the Whitehall study, because they are excellent illustrators of socioeconomic inequalities in health.

\section{Methods}

We drew participants from the west of Scotland twenty-07 study, a population sampled cohort study designed to investigate social gradients in health. The design and sampling have been described in detail elsewhere. ${ }^{19}$ The social class distribution of the study sample (based on the "locality" and the "regional" groups combined) did not differ from a comparable sample of the local population drawn from the UK's 1991 census samples of anonymised records. ${ }^{20}$ The twenty- 07 study comprises three cohorts recruited at 15,35, and 55 years of age from 1987. Our analyses are based on data for the oldest age group collected by trained nurse interviewers in the homes of study participants in 1988 and on subsequent mortality surveillance. 


\section{Assessment of socioeconomic position}

Data for five indicators of socioeconomic position were collected at interview. These comprised four individual or household level markers (education, current and childhood social class, income) and one area based measure of deprivation. Education was recorded as years of full time study. Head of household's current (or last if not currently employed) occupation was coded as one of six categories according to the Registrar General's schema of occupational social class. ${ }^{21}$ Married or cohabiting women were classified according to their partner's occupation. The main occupation of the respondent's father during their childhood (denoted as "childhood social class") was coded to the same sixfold classification. Income was based on total household earnings after tax, including any benefits. Respondents were asked to specify an actual amount in pounds sterling per week, month, or year. If they were unwilling to do so, they were asked to identify an appropriate income band on a preprinted card. Finally, we used the Carstairs-Morris area deprivation score for the postcode sector of residence, derived from four 1991 census variables (overcrowding, male unemployment, low social class, and car ownership), with higher levels indicating greater deprivation. ${ }^{22}$

\section{Assessment of IQ}

IQ was assessed with part I of the Alice Heim 4 test of general intelligence. ${ }^{23}$ This comprises 65 items and measures verbal IQ (32 items) and numeric IQ (33 items). The questions pertain to series completion, mental arithmetic, vocabulary, and reasoning by analogy tasks. Twelve practice items are included, and the test has a 10 minute time limit. Scores from part I of this test correlate strongly $(r=0.66)$ with those from Raven's progressive matrices, a test of non-verbal reasoning that is closely related to general cognitive ability. ${ }^{23}$ The Alice Heim 4 test has been used in other large population based cohort studies of middle aged and older people. ${ }^{184}$ The total score was standardised to zero mean and unit standard deviation.

\section{Assessment of health outcomes}

The 12 item version of the general health questionnaire $\mathrm{e}^{25}$ was used to provide an indication of minor psychiatric illness; a score of three or more symptoms denoted a "case." Respiratory function was assessed by taking the highest of three readings for forced expiratory volume in one second from a Micro Medics spirometer. Scores were standardised by dividing them by the square of height in metres; scores below the median (0.82) denoted low respiratory function. A standard question from the British general household survey was used to ascertain longstanding illness: "Do you have any long-standing illness, disability or infirmity?" ${ }^{26}$ Self assessed health was also derived from a standard inquiry: "Thinking back over the last twelve months would you say that your health has been excellent, good, fair or poor?" (categorised into excellent/good; fair/poor). Study participants were flagged prospectively with the NHS central registry for notification of death and cause. For the purposes of comparability, all the above health indicators were dichotomised.

\section{Statistical analyses}

In order to have all indicators of socioeconomic position and cognition scored in the same direction, we reversed the scoring of education, income, and IQ, so that higher scores reflected the most unfavourable levels (disadvantaged), as was already the case for the original coding of both the markers of occupational social class and the Carstairs-Morris index.

We calculated a relative index of inequality (RII) to quantify the association between socioeconomic position, measured by using a diverse range of indices of socioeconomic indices, and health. ${ }^{27}$ The RII is derived by ranking the participants on each of the socioeconomic measures. For the discrete measures, and in the case of ties for continuous measures, we assigned the mean rank. We then divided these rank scores by the sample size to yield a value between 0 and 1 . For the purposes of interpretation, the RII should be regarded as the relative risk of a given health outcome in the most disadvantaged group relative to the most advantaged. Its interpretation is the same as a relative risk.

We used Cox proportional hazards regression, ${ }^{28}$ as implemented in the SAS Phreg procedure, ${ }^{29}$ to examine the relation between socioeconomic position and mortality outcomes by deriving an RII (hazards ratio), censoring survival time at 31 August 2004. For all other outcome variables, we used logistic regression analyses to calculate an RII (odds ratio). In the first stage of these analyses, we calculated a sex adjusted RII for the relation between each indicator of socioeconomic position and health outcome. We then introduced IQ into the sex adjusted model. We compared sex adjusted RII with sex and IQ adjusted results by quantifying the percentage change in RII, an approach that has been used elsewhere. ${ }^{18} 30$

In all 1347 men and women (mean age 56 (SD 0.6) years at study induction) had full IQ data. The size of the analytical sample varied somewhat owing to the index of socioeconomic position and health used in each statistical model (sample size range: 1143-347).

\section{Results}

After 16 years of follow-up, 362 deaths (166 in women) had occurred; around one third of these $(n=104)$ were attributable to coronary heart disease. Table 1 presents the association of each indicator of socioeconomic position with total mortality and coronary heart disease mortality. In sex adjusted analyses with all cause mortality as the outcome of interest, raised rate ratios were apparent in the most disadvantaged group for each marker of socioeconomic position: income (hazard ratio 2.74, $95 \%$ confidence interval 1.86 to 4.03 ), area deprivation (2.50, 1.74 to 3.60$)$, childhood social class $(2.32,1.55$ to 3.46$)$, current social class (1.70, 1.17 to 2.47 ), and education (1.65, 1.07 to 2.54$)$. Thus, taking the example of childhood social class, the risk of subsequent death in the most disadvantaged group was 2.32 times higher than that seen for the most advantaged group. A similar pattern of risk, but of higher magnitude, was apparent for each indicator of socioeconomic position in relation to coronary heart disease mortality, although confidence intervals were wider owing to the lower number of cases.

When we added IQ to the sex adjusted model we saw a marked decrease in the strength of these gradients. The reduction in RII across the five measures of socioeconomic position ranged from $45 \%$ to $131 \%$ for total mortality and from $31 \%$ to $111 \%$ for coronary heart disease mortality. However, statistical significance at conventional levels held in most analyses; the only exceptions were the total mortality gradients for current social class (hazard ratio $0.96,0.63$ to 1.46$)$ and education $(0.80,0.49$ to 1.31).

Table 2 shows odds ratios for the relation of each measure of socioeconomic position with self reported long term illness and poor self rated health. Again, in the sex adjusted analysis we saw an elevated risk of each of these outcomes in the lower socioeconomic groups. Once more, control for IQ led to substantial attenuation-the reduction in RII ranged from 25\% to 53\% for long term illness and from $41 \%$ to $56 \%$ for poor self rated health. Most of the socioeconomic position-health gradients retained 
Table 1 Relative index of inequality (RII) for the relation of indicators of socioeconomic position to selected health outcomes in the west of Scotland twenty-07 study

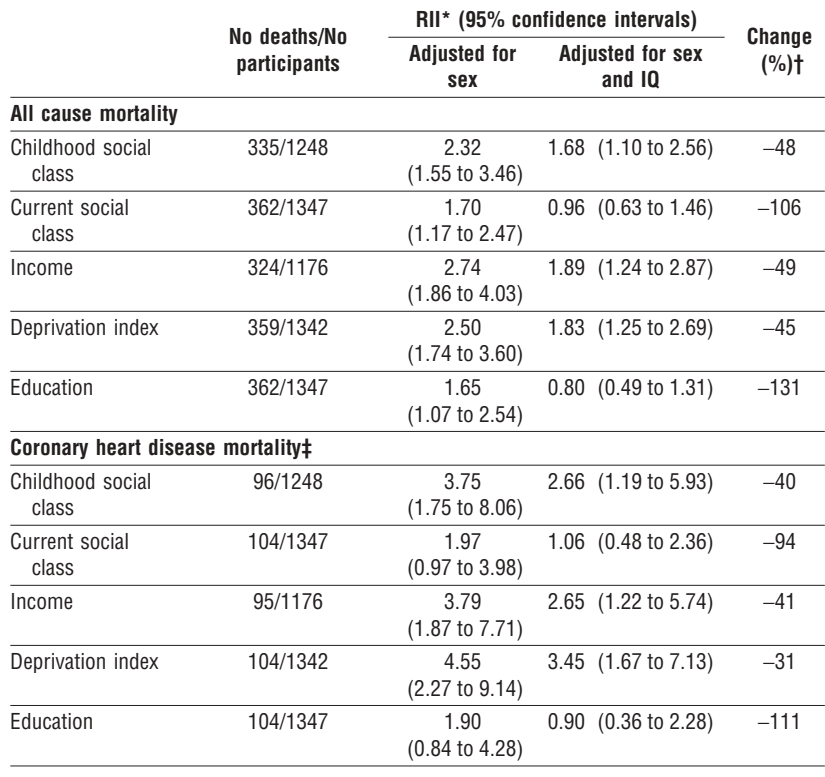

\section{*Hazard ratios.}

tPercentage change in $\mathrm{RII}$ in sex adjusted analyses compared with $\mathrm{RII}$ in sex and IQ adjusted analyses. Calculated by using $\left(\left[R \|_{\text {sex adiusted }}-1\right]-\left[R \|_{10 \text { adjusted }}-1\right] /\left[R I_{\text {sex and } 10 \text { adjusted }}-1\right]\right) * 100$

$\ddagger$ Deaths with ICD-9 (international classification of diseases, 9th revision) codes 410-414.9 or ICD-10 codes I20-125.9.

statistical significance; the only exceptions, again, were low current occupational social class (odds ratio $1.54,0.98$ to 2.41 ) and fewer completed years of education $(1.34,0.80$ to 2.25$)$ in relation to long term illness.

Control for IQ resulted in attenuation of RIIs of between $15 \%$ and $58 \%$ for general health questionnaire "caseness" and

Table 2 Relative index of inequality (RII) for the relation of indicators of socioeconomic position to selected health outcomes in the west of Scotland twenty-07 study

\begin{tabular}{|c|c|c|c|c|}
\hline & \multirow{2}{*}{$\begin{array}{l}\text { No cases/No } \\
\text { participants }\end{array}$} & \multicolumn{2}{|c|}{ RII* ( $95 \%$ confidence intervals) } & \multirow{2}{*}{$\begin{array}{c}\text { Change } \\
(\%) \dagger\end{array}$} \\
\hline & & $\begin{array}{l}\text { Adjusted for } \\
\text { sex }\end{array}$ & $\begin{array}{l}\text { Adjusted for sex } \\
\text { and IQ }\end{array}$ & \\
\hline \multicolumn{5}{|l|}{ Long term illness } \\
\hline $\begin{array}{l}\text { Childhood social } \\
\text { class }\end{array}$ & $788 / 1248$ & $\begin{array}{c}1.81 \\
\text { (1.17 to } 2.77)\end{array}$ & 1.61 (1.02 to 2.52$)$ & -25 \\
\hline $\begin{array}{l}\text { Current social } \\
\text { class }\end{array}$ & $354 / 1347$ & $\begin{array}{c}1.83 \\
(1.23 \text { to } 2.72)\end{array}$ & 1.54 (0.98 to 2.41) & -35 \\
\hline Income & $758 / 1176$ & $\begin{array}{c}2.05 \\
\text { (1.34 to } 3.13 \text { ) }\end{array}$ & 1.78 (1.13 to 2.82$)$ & -26 \\
\hline Deprivation index & $851 / 1342$ & $\begin{array}{c}1.88 \\
(1.27 \text { to } 2.77)\end{array}$ & 1.64 (1.08 to 2.47$)$ & -27 \\
\hline Education & $854 / 1347$ & $\begin{array}{c}1.73 \\
(1.11 \text { to } 2.70)\end{array}$ & $1.34(0.80$ to 2.25$)$ & -53 \\
\hline \multicolumn{5}{|c|}{ Poor self perceived health } \\
\hline $\begin{array}{l}\text { Childhood social } \\
\text { class }\end{array}$ & $527 / 1248$ & $\begin{array}{c}3.55 \\
(2.32 \text { to } 5.43) \\
\end{array}$ & 2.40 (1.53 to 3.76$)$ & -45 \\
\hline $\begin{array}{l}\text { Current social } \\
\text { class }\end{array}$ & $580 / 1347$ & $\begin{array}{c}5.20 \\
\text { (3.47 to } 7.78)\end{array}$ & 3.09 (1.98 to 4.83$)$ & -50 \\
\hline Income & $519 / 1176$ & $\begin{array}{c}5.99 \\
(3.90 \text { to } 9.19) \\
\end{array}$ & 3.81 (2.41 to 6.03$)$ & -44 \\
\hline Deprivation index & $577 / 1342$ & $\begin{array}{c}4.63 \\
\text { (3.13 to } 6.85)\end{array}$ & 3.14 (3.08 to 4.75$)$ & -41 \\
\hline Education & $580 / 1347$ & $\begin{array}{c}6.48 \\
\text { (4.04 to 10.4) }\end{array}$ & 3.40 (1.99 to 5.80$)$ & -56 \\
\hline
\end{tabular}

${ }^{*}$ Odds ratios.

†Percentage change in RII in sex adjusted analyses compared with RII in sex and IQ adjusted analyses. Calculated by using $\left(\left[R \|_{\text {sex adjusted }}-1\right]-\left[R \|_{\text {sex and } 10 \text { adjusted }}-1\right] /\left[R \|_{\text {sex adjusted }}-1\right]\right)^{*} 100$.
Table 3 Relative index of inequality (RII) for relation of indicators of socioeconomic position to selected health outcomes in the west of Scotland twenty-07 study

\begin{tabular}{|c|c|c|c|c|}
\hline & \multirow[b]{2}{*}{$\begin{array}{l}\text { No cases/No } \\
\text { participants }\end{array}$} & \multicolumn{2}{|c|}{ RII* (95\% confidence intervals) } & \multirow[b]{2}{*}{$\begin{array}{c}\text { Change } \\
(\%) \dagger\end{array}$} \\
\hline & & $\begin{array}{l}\text { Adjusted for } \\
\text { sex }\end{array}$ & $\begin{array}{l}\text { Adjusted for sex } \\
\text { and IQ }\end{array}$ & \\
\hline \multicolumn{5}{|c|}{ High general health questionnaire score } \\
\hline $\begin{array}{l}\text { Childhood social } \\
\text { class }\end{array}$ & $291 / 1218$ & $\begin{array}{c}2.03 \\
\text { (1.25 to } 3.31)\end{array}$ & 1.82 (1.09 to 3.04$)$ & -20 \\
\hline $\begin{array}{l}\text { Current social } \\
\text { class }\end{array}$ & $318 / 1312$ & $\begin{array}{c}2.64 \\
(1.67 \text { to } 4.17)\end{array}$ & 2.40 (1.44 to 4.00$)$ & -15 \\
\hline Income & $288 / 1143$ & $\begin{array}{c}3.55 \\
\text { (2.19 to } 5.75)\end{array}$ & 3.17 (1.88 to 5.33$)$ & -15 \\
\hline Deprivation index & $316 / 1307$ & $\begin{array}{c}2.45 \\
(1.57 \text { to } 3.84)\end{array}$ & 2.22 (1.39 to 3.56$)$ & -16 \\
\hline Education & $318 / 1312$ & $\begin{array}{c}1.71 \\
(1.01 \text { to } 2.90)\end{array}$ & 1.30 (0.71 to 2.38$)$ & -58 \\
\hline \multicolumn{5}{|c|}{ Low respiratory function } \\
\hline $\begin{array}{l}\text { Childhood social } \\
\text { class }\end{array}$ & $610 / 1248$ & $\begin{array}{c}3.80 \\
\text { (2.44 to } 5.93)\end{array}$ & 2.57 (1.61 to 4.10$)$ & -44 \\
\hline $\begin{array}{l}\text { Current social } \\
\text { class }\end{array}$ & $653 / 1347$ & $\begin{array}{c}3.55 \\
\text { (2.35 to } 5.37)\end{array}$ & 2.07 (1.31 to 3.28$)$ & -58 \\
\hline Income & $568 / 1176$ & $\begin{array}{c}3.75 \\
\text { (2.44 to } 5.77 \text { ) }\end{array}$ & 2.39 (1.50 to 3.81$)$ & -49 \\
\hline Deprivation index & $651 / 1342$ & $\begin{array}{c}3.34 \\
\text { (2.24 to } 4.98)\end{array}$ & 2.27 (1.48 to 3.46$)$ & -46 \\
\hline Education & $653 / 1347$ & $\begin{array}{c}4.00 \\
\text { (2.50 to } 6.41)\end{array}$ & 2.01 (1.17 to 3.45$)$ & -66 \\
\hline
\end{tabular}

${ }^{*}$ Odds ratios.

†Percentage change in RII in sex adjusted analyses compared with RII in sex and IQ adjusted analyses. Calculated by using $\left(\left[R I_{\text {sex adiusted }}-1\right]-\left[R I_{\text {sex and } 10 \text { adjusted }}-1\right] /\left[R \|_{\text {sex adiusted }}-1\right]\right)^{*} 100$.

$44 \%$ to $66 \%$ for poor respiratory function (table 3). Apart from the association between education and general health questionnaire score (1.30, 0.71 to 2.38), odds ratios remained significantly raised for both these health outcomes in relation to all measures of socioeconomic position.

Taking these results together, the attenuation in effect estimates was higher for the objectively measured health indicators of total mortality and coronary heart disease mortality (range 31-131\%) and respiratory function (44-66\%) than for the self reported measures (15-58\%). Of the 25 separate socioeconomic-health gradients that were statistically significant in sex adjusted analyses, adjustment for IQ led to loss of significance in only one fifth $(5 / 25)$ (we exclude coronary heart disease mortality from this calculation because these deaths were included in total mortality).

\section{Discussion}

The purpose of these analyses was to test the hypothesis that IQ explains socioeconomic differentials in health. We suggested that if this was the case we would expect these inequalities to disappear after statistical control for IQ. In our analyses, only one fifth of socioeconomic-health gradients were reduced to statistical non-significance $(\mathrm{P}>0.05)$, and in half of the associations examined the risk of ill health in the socioeconomically disadvantaged group was still twice that of the advantaged group. These observations notwithstanding, all the relations were markedly attenuated when we added IQ to the sex adjusted models. The degree of this attenuation depended on the indicator of socioeconomic position and health under consideration.

\section{Comparison with other studies}

In this study, the effect of adjusting for measures of IQ on the socioeconomic position-health relation was comparable in magnitude to the impact of adjusting for job control and established physiological and behavioural risk factors for mortality (such as 
raised blood pressure or smoking). ${ }^{30}{ }^{31}$ Although two other studies have reported relevant results, ${ }^{32}{ }^{33}$ in neither was the impact of adjusting for IQ on the socioeconomic position-health gradient the central research question, and the level of detail reported reflects this. To our knowledge, only data from the Whitehall II study have been explicitly used to examine the hypothesis that IQ may explain social inequalities in health. ${ }^{18}$ In our analyses, we have used some of the same health outcomes (general health questionnaire "caseness," self perceived health), the same measure of IQ (Alice-Heim 4 part 1 score), and some similar indicators of socioeconomic position (childhood social class, education).${ }^{18}$ The attenuating effects of adjusting for IQ on the socioeconomic position-health relation in the Whitehall II study were broadly similar to those reported here with these health outcomes. However, we were also able to examine the impact of controlling for IQ on the socioeconomic gradient in total mortality and coronary heart disease mortality. The degree of attenuation was noticeably higher than that seen when self reported long term illness, poor self perceived health, and minor psychiatric disorder were the health outcomes.

\section{Plausible mechanisms}

Several potential explanations exist for the attenuating effect of IQ on the socioeconomic-health gradient, which need not be mutually exclusive. These are beyond the scope of this paper, and have been discussed elsewhere, ${ }^{10}{ }^{34}$ but some observations should be made here. Firstly, IQ is associated with health behaviours that are themselves linked to several of the health outcomes featured here. For instance, people with higher childhood IQ scores are more likely to stop smoking once started than are those with lower IQ scores. ${ }^{35}$ Secondly, IQ may be a record of bodily insults across the life course. IQ assessment in this study took place when the participants were 56 years old. At this age this cohort was characterised by a higher than expected prevalence of poor health, ${ }^{36}$ particularly among the most socially disadvantaged. ${ }^{37}$ Important chronic diseases such as hypertension and diabetes have been shown to lower IQ. ${ }^{38}{ }^{39}$ These conditions may remain hidden but none the less increase mortality risk. Low IQ test scores at this age may thus already reflect deteriorating health, and therefore adjustment for it may, in fact, be partly controlling for subclinical health status at the start of the study.

\section{Study limitations}

One limitation of the study is that we used only a brief (10 minute) paper and pencil test of IQ. Whether an estimate of general mental ability obtained from a longer, more varied, test battery (such as the Wechsler adult intelligence scale) would result in greater attenuation of the social gradients in health remains to be seen. A frequent criticism of written IQ tests, as used here, is their potential cultural bias. In this study, the use of reaction time scores, a culture reduced indicator of cognitive ability that is measured with a simple electronic device, can be used to examine this question. Reaction time correlates moderately strongly with IQ test scores. ${ }^{40}$ The study participant responds as quickly as possible by pressing an appropriate button when one of four possible numbers appears on a screen. The longer the reaction time, the lower the efficiency. Adjusting for reaction time scores in our analyses also produced attenuation in the socioeconomichealth gradients that were marked but marginally weaker compared with adjustment for IQ alone (for a supplementary report refer to www.msoc-mrc.gla.ac.uk/Staff/Biography/ preprint/SEP_IQ_health_T07_supplement_4.pdf).

\section{What is already known on this topic}

Socioeconomic inequalities in health are very well established

Understanding the mechanisms underlying these gradients is crucial if effective population based interventions are to be identified

IQ has recently been suggested to be "the epidemiologists' elusive 'fundamental cause' of social class inequalities in health"

\section{What this study adds}

IQ does not completely explain socioeconomic gradients in health

It does, however, markedly reduce socioeconomic gradients in health, to an extent depending on the indicator of socioeconomic position and health under consideration

\section{Public health implications}

Our findings indicate that measured IQ does not completely account for observed socioeconomic inequalities in health but, probably through a variety of processes, may contribute to them. This implies that efforts to reduce these differentials should continue to be based on a broad front, including educational opportunities and interventions particularly in early life. ${ }^{61}$ Such childhood interventions may also elicit improvements in IQ, although results are mixed. ${ }^{42}$

Interventions need to be based on the best possible evidence about the factors that generate and maintain social and health inequalities. The currently scant information about IQ and health thus needs to be enhanced, with empirical investigation of why IQ seems to predict some health outcomes and how the links between low socioeconomic status, low IQ, and poor health might be broken.

GDB is also affiliated with the Department of Psychology, University of Edinburgh, Edinburgh. We thank the field workers, clerical staff, and research participants for their contributions to the twenty-07 study. Archana Singh-Manoux and coworkers kindly sent us a pre-publication copy of their paper. ${ }^{18}$

Contributors: GDB had the idea for this paper, which was developed by GD, IJD, and SM. GD analysed the data. GDB wrote the first draft; GD, SM, and IJD contributed to all revisions. GDB and GD are the guarantors.

Funding: The west of Scotland twenty-07 study is funded by the UK Medical Research Council, as are SM and GD. IJD is the recipient of a Royal Society-Wolfson research merit award. GDB holds a Wellcome advanced training fellowship (No 071954/Z/03/Z).

Competing interests: None declared.

Ethical approval: Ethics committee approval for the twenty-07 study was granted by the general practice subcommittee of the Greater Glasgow Health Board Area Medical Committee, and the West of Scotland General Practice Ethical Committee.

1 Chief Medical Officer. Health in Scotland 2004. Edinburgh: Scottish Executive, 2005. 2 Department of Health. Choosing health:making healthy choices easier. London: Stationery Office, 2004.

3 US Department of Health and Human Services. Healthy people 2010. Washington DC: US Government Printing Office, 2000.

Marmot M. Social determinants of health inequalities. Lancet 2005;365:1099-104.

Wilkinson R, Marmot M. Social determinants of health: the solid facts. Copenhagen: World Health Organization, 2003.

6 Acheson D. Independent inquiry into inequalities in health: report. London: Stationery Office, 1998.

7 Gordon D, Shaw M, Dorling D, Davey Smith G. Inequalities in health. Bristol: Policy Press, 1999.

1999.
Taylor SE, Repetti RL, Seeman T. Health psychology: what is an unhealthy environment and how does it get under the skin? Annu Rev Psychol 1997;48:411-47. 
9 Gottfredson LS. Intelligence: is it the epidemiologists' elusive "fundamental cause" of social class inequalities in health? J Pers Soc Psychol 2004;86:174-99.

10 Whalley LJ, Deary IJ. Longitudinal cohort study of childhood IQ and survival up to age 76. BMJ 2001;322:819.

11 Batty GD, Mortensen E, Nybo Andersen A-M, Osler M. Childhood intelligence in relation to adult coronary heart disease and stroke risk: evidence from a Danish birth cohort study. Paediatr Perinat Epidemiol 2005;19:452-9.

12 Batty GD, Mortensen EL, Osler M. Childhood IQ in relation to later psychiatric disorder: evidence from a Danish birth cohort study. Br J Psychiatry 2005;187:180-1.

13 O'Toole B, Stankov L. Ultimate validity of psychological tests. Pers Individ Dif 1992;13:699-716.

14 Deary IJ, Der G. Reaction time explains IQ's association with death. Psychol Sci $2005 \cdot 16 \cdot 64-9$

15 Pavlik VN, de Moraes SA, Szklo M, Knopman DS, Mosley TH Jr, Hyman DJ. Relation between cognitive function and mortality in middle-aged adults: the atherosclerosis risk in communities study. Am J Epidemiol 2003;157:327-34.

16 Kelman HR, Thomas C, Kennedy GJ, Cheng J. Cognitive impairment and mortality in older community residents. Am J Public Health 1994;84:1255-60.

17 Neisser U, Boodoo G, Bouchard Jr TJ, Boykin AW, Brody N, Ceci SJ, et al. Intelligence: knowns and unknowns. Am Psychol 1996;51:77-101

18 Singh-Manoux A, Ferrie J, Lynch J, Marmot M. The role of cognitive ability (intelligence) in explaining the association between socioeconomic position and health: evidence from Whitehall II prospective cohort study. Am J Epidemiol 2005; 161:831-9.

19 MacIntyre S, Annandale E, Ecob R, Ford G, Hunt K, Jamieson B, et al. The west of Scotland twenty- 07 study: health in the community. In: Martin C, MacQueen D, eds. Readings for a new public health. Edinburgh: Edinburgh University Press, 1989

20 Der G. A comparison of the west of Scotland twenty-07 study sample and the 1991 census SARs. Glasgow: MRC Medical Sociology Unit, 1998.

21 Office of Population Censuses and Surveys. Classification of occupations 1980. London HMSO, 1980.

22 Carstairs A, Morris R. Deprivation and health in Scotland. Aberdeen: Aberdeen University Press, 1991.

23 Heim A. Manual for the AH4 group test of general intelligence. Windsor, England: National Foundation for Educational Research, 1970.

24 Rabbitt P, Diggle P, Smith D, Holland F, McInnes L. Identifying and separating the effects of practice and of cognitive ageing during a large longitudinal study of elderly community residents. Neuropsychologia 2001;39:532-43.

25 Goldberg D. The detection of psychiatric illness by questionnaire. London: Oxford University Press, 2004.

26 Office of Population Censuses and Surveys. General household survey 1988. London: HMSO, 1990

27 Mackenbach JP, Kunst AE. Measuring the magnitude of socio-economic inequalities in health: an overview of available measures illustrated with two examples from Europe. Soc Sci Med 1997:44:757-71.

28 Cox DR. Regression models and life-tables. JR Stat Soc [Ser B] 1972;34:187-220.

29 SAS Institute. SAS/STATA user's guide (version 8). Cary, NC: SAS Institute, 1999.
30 Bosma H, Schrijvers C, Mackenbach JP. Socioeconomic inequalities in mortality and importance of perceived control: cohort study. BMJ 1999;319:1469-70.

31 Marmot MG, Shipley MJ, Rose G. Inequalities in death-specific explanations of a general pattern? Lancet 1984;1:1003-6.

32 Hart CL, Taylor MD, Davey Smith G, Whalley LJ, Starr JM, Hole DJ, et al. Childhood IQ social class, deprivation, and their relationships with mortality and morbidity risk in later life: prospective observational study linking the Scottish mental survey 1932 and the midspan studies. Psychosom Med 2003;65:877-83.

33 Osler M, Andersen AM, Due P, Lund R, Damsgaard MT, Holstein BE. Socioeconomic position in early life, birth weight, childhood cognitive function, and adult mortality: longitudinal study of Danish men born in 1953. J Epidemiol Community Health 2003;57:681-6.

34 Batty GD, Deary IJ. Early life intelligence and adult health. BMJ 2004:329:585-6.

35 Taylor MD, Hart CL, Davey Smith G, Starr JM, Hole DJ, Whalley LJ, et al. Childhood mental ability and smoking cessation in adulthood: prospective observational study linking the Scottish mental survey 1932 and the midspan studies. J Epidemiol Commu nity Health 2003;57:464-5.

36 West P, Ford G, Hunt K, MacIntyre S, Ecob R. How sick is the west of Scotland? Age specific comparisons with national datasets on a range of health measures. Scott Med J 1994;39:101-9.

37 Ford G, Ecob R, Hunt K, MacIntyre S, West P. Patterns of class inequality in health through the lifespan: class gradients at 15,35 and 55 years in the west of Scotland. Soc Sci Med 1994;39:1037-50.

38 Manolio TA, Olson J, Longstreth WT. Hypertension and cognitive function: pathophysiologic effects of hypertension on the brain. Curr Hypertens Rep 2003;5:25561.

39 Awad N, Gagnon M, Messier C. The relationship between impaired glucose tolerance, type 2 diabetes, and cognitive function.J Clin Exp Neuropsychol 2004;26:1044-80.

40 Deary IJ, Der G, Ford G. Reaction times and intelligence differences: a population-based cohort study. Intelligence 2001;29:389-99.

41 Black D, Morris J, Smith C, Townsend P. Inequalities in health: report of a working party. London: Department of Health and Social Security, 1980.

42 Mackintosh N. IQ and human intelligence. Oxford: Oxford University Press, 1998. (Accepted 22 December 2005)

doi 10.1136/bmj.38723.660637.AE

MRC Social and Public Health Sciences Unit, University of Glasgow, Glasgow G12 $8 \mathrm{RZ}$

G David Batty Wellcome fellow

Geoff Der statistician

Sally Macintyre director

Department of Psychology, University of Edinburgh, Edinburgh

Ian J Deary professor of differential psychology

Correspondence to: G D Batty david-b@msoc.mrc.gla.ac.uk 